\title{
Scientific Research and Human Resources Potential of Russia's Innovative Environment
}

\section{Научно-исследовательский и кадровый потенциал инновационной среды России}

\author{
Written by: \\ Sergey Novikov ${ }^{1}$ \\ https://orcid.org/0000-0001-6921-1760 \\ https://www.scopus.com/authid/detail.uri?authorId=57192318711 \\ elibrary.ru: https://elibrary.ru/author_profile.asp?id=807011
}

\begin{abstract}
Personnel shortage in developed economic systems of the countries, especially in the field of intellectual activity, is getting worse because of the adverse demographical situation. Considering the mentioned above, this article shows the author's way of dealing with the problem of qualified personnel shortage in the field of Russian science. The author of the article gives a list of suggestions that can help to create favourable conditions for career growth of the scientific and educational personnel and the system of work motivation, to increase the flow of new personnel in science, education and high technology field and to secure it in innovation and scientific field.
\end{abstract}

Keywords: career growth, personnel management, professional career, research, staff shortage.

\section{Introduction}

With the increase of the importance of science in economically developed countries, the renewal of socio-professional structure of society becomes more and more relevant. This renewal consists on the increase of professional mobility and the need of constant education of workers in most economical and service fields. However, the inertia and conservatism of the socio-professional structure as an organic component of aging process prevent us from fully disclosing fully this objective (Vol'chik, Oganesyan, 2017).

The desire to increase the dynamics of social structure gives us the increased speed of generation change by establishing upper limits of working age

\begin{abstract}
Аннотация
Кадровый дефицит в экономике развитых стран сегодня усугубляется неблагоприятной демографической ситуацией. Автором дан ряд предложений с целью создания благоприятных условий для карьерного роста научных кадров на рынке труда, стимулирования притока молодых кадров в научную сферу, сферу образования и высоких технологий.
\end{abstract}

Ключевые слова: исследователь, кадровый дефицит, карьерный рост, профессиональная карьера, ротация кадров, управление персоналом.

restrictions and significant rejuvenation of personnel. This process does not always give good results, because innovative production requires both young specialists and highly skilled personnel who have modern knowledge and highly developed adaptation abilities (Novikov, Veas Iniesta, 2018).

As a result, there is an acute shortage of innovation specialists, who can combine production and scientific creativity to increase competitiveness in international market of goods and services. So, the problems of dynamic of professional structure overflow the national framework in the field of the migration (Novikov, 2018).

\footnotetext{
${ }^{1}$ Institute of Engineering Economics and Humanities Moscow Aviation Institute (National Research University) Moscow, Russia
} 
Personnel shortage in economies of developed countries, especially in the intellectual activity field, is worsen by adverse demographic conditions. In Russia it is not only caused by a natural decrease of birth rate, but also because of the demographic hole. By the year 2019 the number of postgraduate students decreased by 35-40\% (Epstein, 2009).

The researches of the career phenomenon is versatile and follow several directions: psychological and acmeological researches of career motivation (McWhirter E. H., 1998), factors of personality development of the career advancement and growth of individual career (Boser, R.A., Palmer, J.D. \& Daugherty, M.K., 1998), pedagogical researches on problems of professional self-determination and preparedness of school students to choose profession (Sokolov A. S., Sergeev M. G., I. S., Samokhin, 2018, Shchepkina N. To., 2017).

The concept of "career competence" appeared not so long ago in the works of foreign scientists. This concept was developed in the works of Russia's scientists in the following directions: psychological and acmeological researches of the essence and structure of career competence as the integral part of the professional (Bogdanov S. A., Vyatkina, L. B., 2017, Volchik V. V., Oganesyan A. A., 2017), selfrating of career competence of teaching staff (Marolewska K. T., 2017), professionalism of educator (Gluzman N. Ah. Gorbunova N. In., 2017), pedagogical researches on conditions to increase professional competence of educators through the increasing of their career competence (S. A. Smirnov, 1999, Gladkikh V. G., Petrov A. S., 2017; Korneva O. N., Reshetnikova T. K., 2017).

\section{Methodology}

Methodical instrument of the research includes general scientific and economical methods. It represents a synthesis of abstractive theoretical analysis, systematic factor, structural and functional analysis, logical approach, statistical methods, simulation, situational and quantitative approaches. We also use the individual methodical instruments of economic, mathematical modelling, etc.

The informative and normative-legal bases of research are the following: statistical data, data reports of executive authority, materials of monographs and periodicals, Internet resources of the leading research centers of Russia and the results of their own research. We also use Decrees of the President of Russia, resolutions of the Federal government, other normative legal and methodical documents of legislative and Executive authorities of all levels of power of the Russian Federation, including program documents (Novikov, Veas Iniesta, 2018).

\section{Results}

The role of human factor in solving the problems of accelerating the socio-economic development of a country is constantly increasing. That fact is proved by the creation of new requirements for specialists. This leads to new problems for forming the personality of educators and skills of professional interactions. The vital activity under this growth rates requires the full functioning of it as personality: the ability to self-determination, personal and professional self-improvement.

The pedagogical field requires people who can make responsible decisions in situations of choice and predict their possible consequences. They also have to be ready to cooperate, do creative activity, and be open to new experience and aware of their selfesteem.

The problem of professional and personal growth of university teachers is still insufficiently investigated. Nevertheless, development of his professional activity is already in focus of psychology. This way, besides common and intellectual culture tied with positive personality development, it is important for the educator to have communication culture and social interaction based on respect for the dignity of another person and self-preservation.

Russian scientists are focused on scientific mobility, they want to improve scientific qualification, to protect academic degree, to receive scientific title and to be appointed to a higher scientific position (Marulevska, 2017). The listed status movements are closely associated with the growth of material wellbeing of the scientist. However, there is an obstacle on the path of career acceleration, making a research career unattractive for the youth. The survey of researchers in Russia showed the following stages of the average duration of career growth: scientific development - 10 years, achieve scientific recognition - 15 years, achieving the status of manager -15 years, achieving decent salary -15 years. So, the majority of the expected career achievements of researchers come around the age of 40-42 (Epstein, 2009). The longest period of career growth of researchers is observed in the technical and natural science industries. In research organizations there is a shortage of the following specialists: engineers from different directions, programmers, quality control managers, biologists and biotechnologists, ichthyologists, highly qualified electronics engineer, geneticist, meteorologist, nanotechnology worker, patent 
specialist, managers for the advancement of innovation in production, experts on the implementation of development and advancement on the market of innovative products, experts in the field of applied physics, breeders and chemiststechnologists (Stricker, 2016).

The interaction between higher educational institutions and manufacturing companies on the matter of preparing the specialists who can effectively take part in realization of applied scientific researches in organization of innovation manufacturing leaves much to be desired. As shown by the results of the all-Russian expert survey, only half of the universities carry out a large program of activities together with a partner company for training and professional development of specialists who can take part in science projects (Gladkih, Petrova, 2017). The General situation is:

- $\quad$ the development of the system of practices and internships of university students in manufacturing companies is generally well established, but a quarter of universities do not have such an opportunity;

- the participation of production companies in the improvement of educational programs of universities and participation of employees in teaching at universities is "average", as $40 \%$ of universities do not take part in these processes;

- the coordination with production companies of programs to improve the quality of education and training for companies takes place in $55 \%$ of universities;

- the development of the system of practices and internships in the companies of researchers and university professors has a negative trend, as it is typical for less than half of universities (45\%).

From 2010 to 2017, there was a reduction in the number of researchers in the following areas of science: natural sciences - $10.5 \%$, technical sciences $-0.23 \%$, agricultural sciences $-18.78 \%$. During the same period, the number of researchers in the social sciences increased by $26.34 \%$ and in the humanities by $8.8 \%$ (Federal State Statistics Service data).

The share of researchers under the age of 29 in 2017 amounted to $18.45 \%$ of the total number of researchers. The average age of researchers is steadily declining: in 1994 it was 45; in 2000, 50-59; and in $2017,30-39$. It should be noticed that the largest number of researchers are the candidates of sciences (20 772 people), aged 30-39, which indicates a positive trend, as there is large influx of young people in science. The reason is the increasing prestige of science in the eyes of young people (Federal State Statistics Service data) (Korkmaza, 2015).

Postgraduate studies are an important source of scientific personnel. However, due to the impact of the demographic hole, which will last until 2020, the sources of formation of intellectual workers will be reduced. The medium-and long-term forecasts implemented in 2017 illustrate the following situation.

In comparison with 2010, by 2025 the preparation of postgraduate students is expected to be reduced. Accordingly, during the same period, the number of postgraduates from postgraduate school will be reduced (Figure 1).

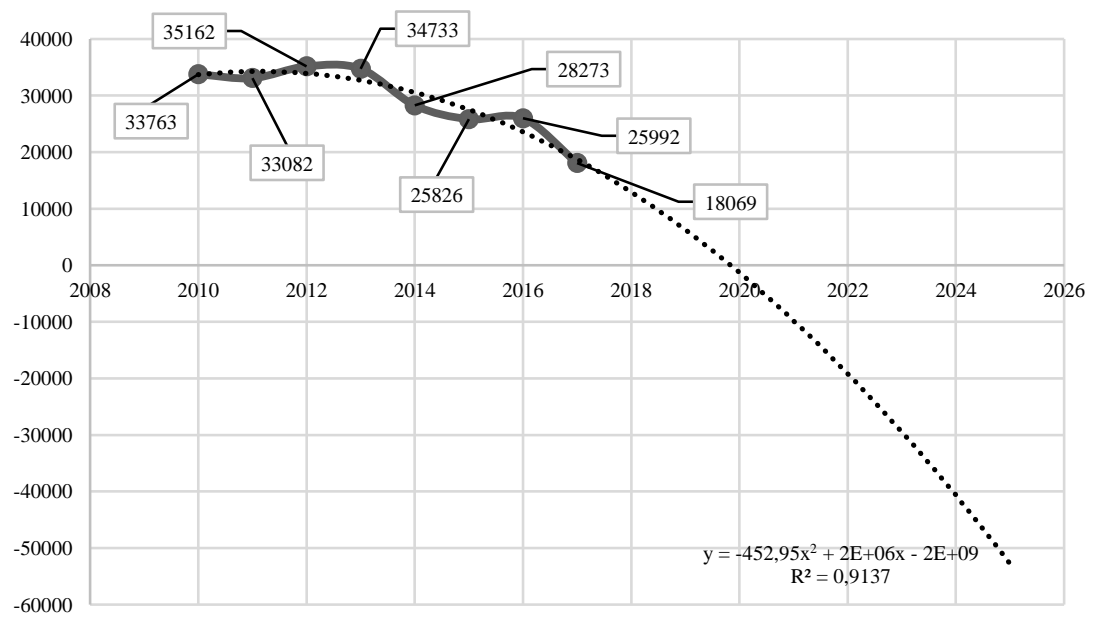

Fig. 1. Number of postgraduate students and the prediction until the year 2025. Source: Federal State Statistics Service data 
By the year 2025, compared with 2010, the number of overall high school postgraduates (Bachelor's degree + Master's degree + Specialist degree) will decrease (Figure 2). This will lead to a reduction in the number of university teachers by 2025 compared to 2010 (Figure 3).

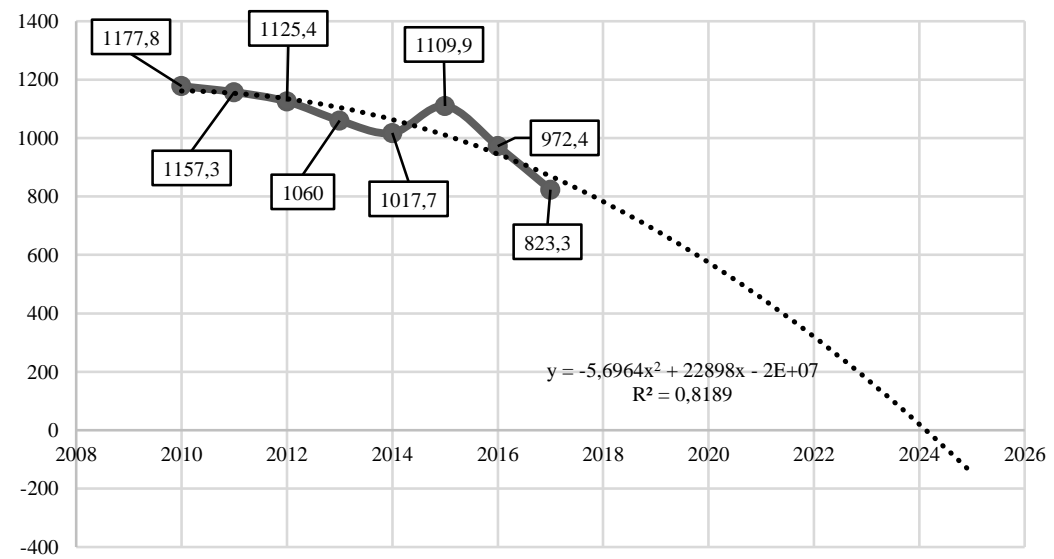

Fig. 2. Number of students graduated from state and municipal educational institutions of higher education of the Russian Federation and forecast until 2025 (divided by 1000). Source: Federal State Statistics Service data

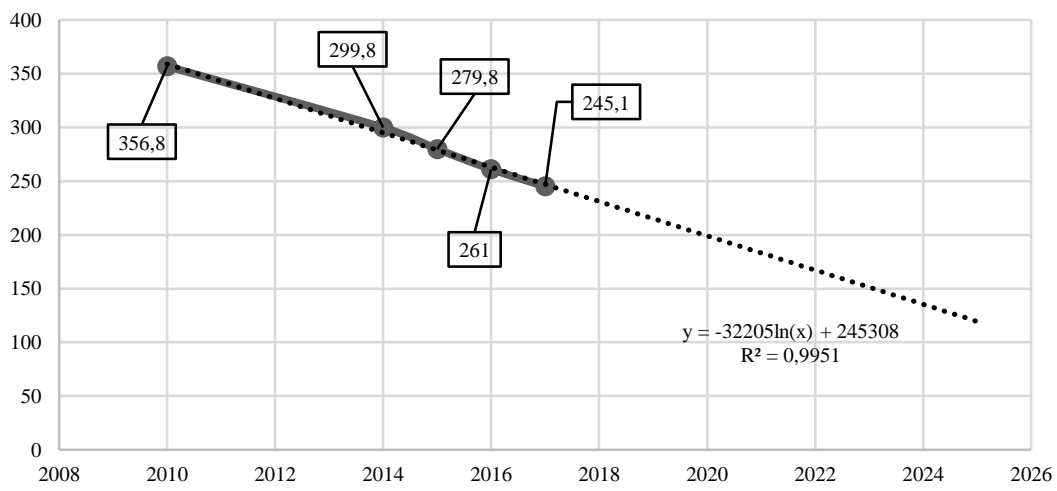

Fig. 3. Number of teaching staff of state and municipal educational institutions of higher education of the Russian Federation and forecast until 2025 (divided by 1000). Source: Federal State Statistics Service data

Considering the dynamics of release from the graduate school and universities, the forecast of the number of researchers is the following: in comparison with 2010, by 2025 the number of research personnel in organizations will be reduced by approximately $23 \%$. (Figure 4 ). 


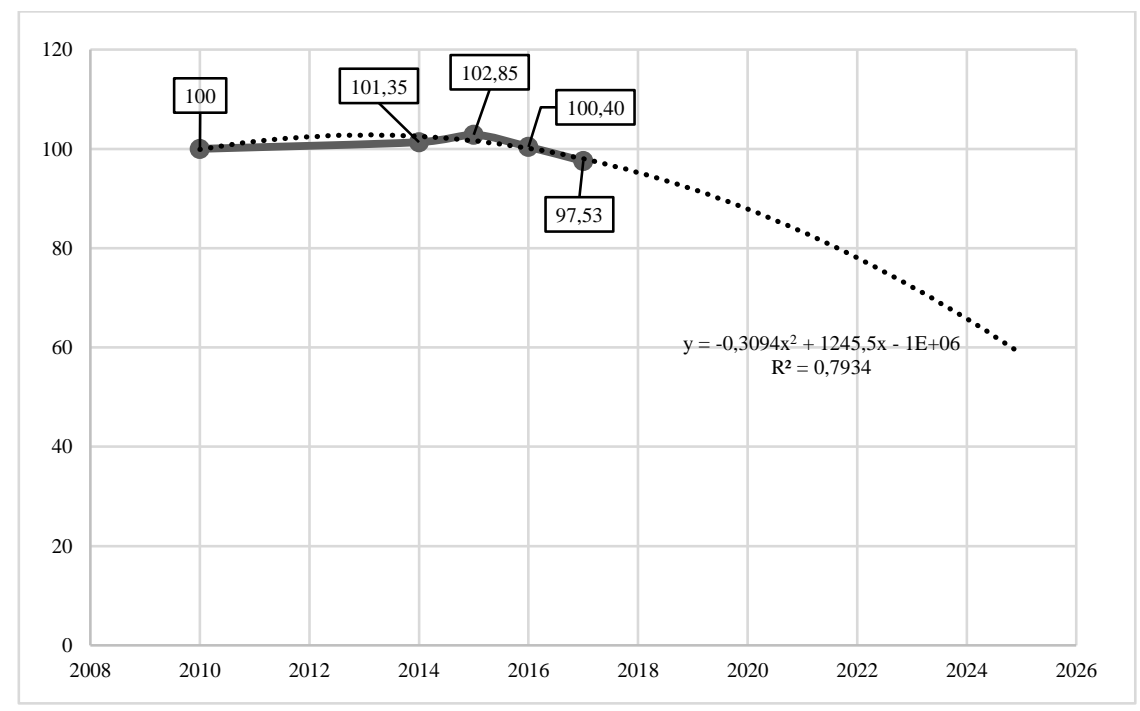

Fig. 4. Share ratio of researchers engaged in research and development in the Russian Federation and forecast to 2025 in relation to 2010, \%. Source: Federal State Statistics Service data

\section{Conclusion}

The released teaching staff can be involved in science, but the effect of such step is unknown, as the scientific potential of the released staff of educators is not evident. This way, there will not be any increase in the number of researchers by 2025 if current conditions of a complete set of the personnel of the research organizations is preserved.

The reduction in the number of staffs of research organizations can be significantly higher than the above forecast indicators due to the increase in the average age of researchers, which remains the same as it was in the 2000. As statistics shows, in 2017 it was 30-39.

There are also serious problems in preparing science personnel in postgraduate study. Since the mid1990s, Russia has seen a rapid increase in the number of postgraduate students due to increased admission to postgraduate study, as well as the opening of new ones, mainly in universities. For the period 1995-2012, the number of postgraduate students increased 2.4 times, in universities, 2.6 times and in research institutes, 1.3 times. Only in 2013 the number of postgraduates started to decrease, mainly because of demographical hole. These data suggest that over the past 10-15 years, postgraduate study has lost its academism and the mass of training is equal to the intellectual level of simple university trainings. It is impossible today to say that postgraduate study prepares only scientists and educators. Most postgraduate students are far from these professions. In some way, the function of postgraduate study has become "amorphous" (Novikov, 2018). The motivation for at least half of future graduate students to study in graduate school is not clear. Most of them go to postgraduate study right after completion of university, without any experience on work or using any of their gained knowledge on practice. In 2010 there were $3.7 \%$ of students started the postgraduate study a few months after the graduation, in $2017-3.2 \%$ and in total with the number of not working in the period between graduation and start of the postgraduate study - $4 \%$ (Korneva, Reshetnikova, 2017).

When deciding to go to postgraduate study, at least half of postgraduate study associate this step with the intention to engage in science in the future. This good indicator has remained virtually unchanged since 2000. According to the results of the study, over the past 19 years the hierarchy of motives for admission to postgraduate study as a whole has not changed. First, it is the desire to engage in science or teach at the university. However, among those who start the postgraduate study there were students with the desire to engage in scientific work professionally. By the end of the study no more than $30 \%$ desire it yet (another one third wants to be university teacher, but not scientist and another one third wants to work in a factory).

The share of postgraduate students who defended their dissertation in 2017, relative to the total output of postgraduate students in the same year was $8.9 \%$. It is less than it used to be in 2000 (17.4\%). "Blank" 


\section{Economics Journal}

work, as a preparation of specialists of intellectual work of the highest qualification, is a characteristic of postgraduate study in all areas of science (especially in social sciences). It is noteworthy that almost $43.5 \%$ of postgraduate students specialize in humanities and social sciences, while the share of researchers working in this field is slightly more than $5 \%$.

The spread of candidate diplomas in a wide range of professions that are not related to universities and research institutions devalued the status of university teachers and academic scientists. They have lost the symbol of their importance and professional identity. Besides, as the country entered the market, the main criterion of professional suitability in high-tech enterprises and design and engineering bureaus is the level of creativity and practical skills. This makes the role of candidate's diploma unclear (Mitrofanova, Demjanchenko, Novikov, Rudakova, Shmanev, 2017).

Experience in the development of modern science (Henry Ford, Bill Gates, Steve Jobs, Mark Zuckerberg and also many constructors of the past in automotive, aviation, rocketry, industry such as Gregor Mendel), paleontology and anthropology (the Catholic priest Teilhard de Chardin) suggests that the personnel of the Russian science should abolish the requirement of mandatory protection of the scientific dissertation, or rather, obtaining a degree. Firstly, excessively bureaucratic form of self-affirmation in science through near-science compilations (like dissertations) has nothing to do with science practice. Secondly, science cannot be taught if it is not given genetically. For researchers the form of targeted self-education is only one acceptable (Verma, 2004).

For collectives engaged in applied research, it is necessary to exclude such criterion of efficiency of scientific work as publication activity, because it distracts the researchers from substantial work. It is well known that no researcher who develops an applied task will not publish the results of his scientific work, especially of commercial interest, neither never, nor before patenting or introduction into production (Novikov, Dmitriev, 2018).

The salary of a university teacher leaves much to be desired. According to the Federal statistics service in 2016, the average salary of a teacher of educational institutions of higher education in the Russian Federation was 49991 rubles, in January 2018 77167 rubles. But the main reason for the increase of salary was caused by the reduction of the number of the teachers (in 2017, compared to 2016, the number of teaching staff of state and municipal educational institutions of higher education of the Russian Federation decreased by 15.9 thousand people) and the increase due to this the workload twice. We should also note that the statistics are overstated, the real average salary of a postgraduate student teaching at the university is half or even one third of these numbers. Since the calculation of the average monthly salary of employees of educational institutions summed up the salary of the rector and the teacher. This is not attractive for postgraduates whose professional plans are predetermined not by the social significance of a particular profession, but by its prestige and profitability. According to the last two criteria, such professions as scientist or university teacher today cannot compete with the professions of economist, lawyer, designer or manager.

Therefore, to improve the career of a university teacher, it is necessary to financially support graduate students, stimulate their interest in achieving scientific discoveries. It should be highlighted that professional development within the profession of a university teacher has its own specifics: the choice of career path depends on the interests, professional attitudes and motives of professional activity. Therefore, the career is a result of successful professional activity of the teacher, aimed at the realization of personal and business potential. Thus, it is in the teaching profession that the development of professional and personal potential and material stimulation of graduate students is an indispensable condition for achieving professionalism and career advancement.

\section{References}

Epstein I. (2009). Life science careers: how to make best use of Europe's brains. New Biotechnology. 25(6), 389.

Gladkih V.G., Petrova A.S. (2017). Design of pedagogical career as a target strategy of personal and professional development of the future teacher of professional training. Book of Scientific and practical conference with international participation «Strategic directions of education development in the Orenburg region». 44-56.

Korkmaza H. (2015). Factors Influencing Students' Career Chooses in Science and Technology: Implications for High School Science Curricula. Procedia - Social and Behavioral Sciences. 197, 966972.

Korneva O.N., Reshetnikova T.K. (2017). Language training of teachers-lawyers as a way of professional growth growth in modern conditions. Book of Scientific and practical conference with international participation «Humanitarian education and science in a technical University». 15, 541-546. 
Marulevska K.T. (2017). Qualification and career growth of pedagogical specialists in the aspect of legal dynamics in the Bulgarian educational system. International book of scientific works dedicated to the 90th anniversary of Professor S. P. Baranov "Epistemological foundations of education». 169174.

Mitrofanova S.V., Demjanchenko N.V., Novikov S.V., Rudakova O.V., Shmanev S.V. (2017). The role and characteristics of the enterprises' working conditions before and after the transition to market relations: A view from macroeconomic perspective. International Journal of Applied Business and Economic Research. 15(13), 63-72.

Novikov S.V. (2018). Russian Support for Innovation and Export Growth. Russian Engineering Research. 38(4), 305-308.
Novikov S.V. (2018). Russian Support for Innovation and Export Growth. Russian Engineering Research. 38(4), 305-308.

Novikov S.V., Dmitriev O.N. (2018). Vision of Genesis of Presentation of Hi-Tech Project during Competitive Selection. Russian Engineering Research. 38(4), 320-322.

Novikov S.V., Veas Iniesta D.S. (2018). State regulation of the development of the connectivity of the Russian territory. Espacios. 39(45).

Stricker E.M. (2016). Distinguished career award: Reflections on a career in science. Physiology \& Behavior. 162, 196-200.

Verma I.M. (2004). The Long Path to a Career in Science. Molecular therapy, 9(3).

Vol'chik V.V., Oganesyan A.A. (2017). Reforms in education: the burden of adaptation. Terra Economicus. 15(4), 136-148. 